\title{
Efeitos colaterais da ranitidina aplicada em dose terapêutica em cães saudáveis
}

\author{
Adverse effects of ranitidine applied in therapeutic dosage in healthy dogs \\ Guilherme Albuquerque de Oliveira Cavalcanti* ${ }^{\text {* }}$ Marcus Antônio Rossi Feliciano ${ }^{\mathrm{II}}$ \\ Tatiana Silveira ${ }^{\mathrm{III}}$ Carlos Artur Lopes Leite ${ }^{\mathrm{IV}}$ Roberto Baracat Araújo ${ }^{\mathrm{I}}$
}

\section{RESUMO}

O objetivo deste trabalho foi verificar se a dose de ranitidina $2 \mathrm{mg} \mathrm{kg}^{-1}$, aplicada via intravenosa, causa êmese ou hipotensão em cães saudáveis. Foram selecionados 10 cães da raça Retriever do Labrador, 10 da raça Beagle e 10 cães sem raça definida, sendo cinco animais de cada sexo. Os animais foram submetidos ao exame clínico e à avaliação da pressão sanguínea antes da aplicação do fármaco e também 10 minutos e quatro horas após a administração deste. Após a aplicação, observou-se que 13,3\% dos animais apresentaramse normais; 6,7\% dos cães apresentaram apatia; 50\% dos animais apresentaram salivação e $30 \%$ apresentaram apatia, salivação, mímica de vômito ou êmese. Não houve diminuição significativa da pressão arterial após a administração do fármaco. Conclui-se que o uso de ranitidina na dose terapêutica, aplicada via intravenosa, pode provocar apatia, salivação, mímica de vômito e êmese.

Palavras-chave: ranitidina, caninos, efeitos indesejados, vômito.

\section{ABSTRACT}

The purpose of this study was to verify if the ranitidine dosage of $2 \mathrm{mg} \mathrm{kg}^{-1}$ by intravenous path causes emesis or hypotension in healthy dogs. They were selected 10 Labrador Retriever, 10 Beagles and 10 mongrel dogs, five animals of each sex. The animals were submitted to clinical examination and blood pressure evaluation before ranitidine administration and also 10 minutes and 4 hours after administration of it. After administration was observed that $13.3 \%$ of the animals presented normal; $6.7 \%$ of the dogs presented apathy; $50 \%$ of the animals presented salivation and $30 \%$ presented apathy, salivation, emesis mimic or emesis. There was no significative arterial blood pressure decrease after ranitidine administration.
It was concluded that ranitidine useful in therapeutic dosage by intravenous path may provoke apathy, salivation, emesis mimic and emesis.

Key words: ranitidine, canines, undesired effects, emesis.

\section{INTRODUÇÃO}

As lesões da mucosa do trato gastrintestinal de cães e gatos podem ser causadas por várias condições. A uremia na insuficiência renal crônica, o estresse prolongado, a administração de antiinflamatórios não esteroidais, alguns antibióticos (como a cefalexina) e o jejum prolongado podem levar a lesões no epitélio do trato digestivo, sendo indicados medicamentos que minimizem esse dano. Os medicamentos antiácidos diminuem a acidez no trato gastrentérico, minimizando os danos à mucosa (SPINOSA, 1996).

Os ácidos gástricos são secretados na membrana apical da célula parietal estomacal. A histamina estimula sua liberação e também causa vasodilatação (OKABE et al., 2001; MCCORD et al., 2006). Os antagonistas de receptores $H$ mais comuns são a cimetidina, a ranitidina, a famotidina, a roxatidina e a nizatidina (ISHIKAWA et al., 1999).

A ranitidina é um fármaco amplamente utilizado na clínica de pequenos animais (SPINOSA, 1996; ETTINGER \& FELDMAN, 1997). É um inibidor

'Universidade Federal de Minas Gerais (UFMG), 31270-901, Belo Horizonte, MG, Brasil. E-mail: cavalcantigui@gmail.com.

*Autor para correspondência.

"Universidade Estadual Paulista (UNESP), Campus Jaboticabal, Jaboticabal, SP, Brasil.

IIIAutônoma, Lavras, MG, Brasil.

${ }^{\mathrm{IV}}$ Universidade Federal de Lavras (UFLA), Lavras, MG, Brasil. 
competitivo reversível da ação da histamina nos receptores $\mathrm{H}_{2}$, incluindo os receptores das células parietais gástricas e inibindo a secreção ácida estomacal (HONG, 2006). Esse fármaco é altamente seletivo para os receptores $\mathrm{H}_{2}$ (MCCORD et al., 2006). Seu metabolismo é principalmente renal e sua principal via de excreção é a urinária (SPINOSA, 1996).

A ranitidina é indicada em casos de gastrenterites, úlceras gastroduodenais, refluxo gastroesofágico, esofagite, sendo administrada a cada oito horas, na dosagem de $2 \mathrm{mg} \mathrm{kg}^{-1}$, nas seguintes vias: oral, subcutânea, intramuscular ou intravenosa (IV) (SPINOSA, 1996; ETTINGER \& FELDMAN, 1997).

Segundo MCCORD et al. (2006), a ranitidina não apresenta ação no sistema nervoso central, efeitos cardiovasculares diretos ou ações sedativas. Contudo, pode causar vômitos, diarreia, sinais neurológicos e hipotensão, principalmente quando utilizada em sobredosagem (CHRUSCH et al., 1999; MCCORD et al., 2006). Sabe-se que cães recebendo doses maiores que $225 \mathrm{mg} \mathrm{kg}^{-1} \mathrm{dia}^{-1}$ podem apresentar tremores musculares, vômito e taquipneia (SPINOSA, 1996).

Como não foi encontrado, na literatura pesquisada, estudo específico de avaliação da provável indução do vômito observada na prática clínica com o uso da ranitidina, na dose de $2 \mathrm{mg} \mathrm{kg}^{-1}$, IV, objetiva-se, com este trabalho, relatar os sinais clínicos gastrentéricos e a possível diminuição da pressão arterial observados em cães saudáveis, após a aplicação desse fármaco nessas dose e via.

\section{MATERIAL E MÉTODOS}

Foram selecionados 30 cães, sendo 10 animais da raça Retriever do Labrador, com peso médio de 21,71 2 ,73kg e com 15 meses de idade; 10 da raça Beagle, com peso médio de 8,78 1 1,83kg e com 15 meses de idade; e 10 cães sem raça definida, com peso médio de $14,42 \pm 5,23 \mathrm{~kg}$ e idade variando de um a seis anos. Em cada grupo, foram utilizados cinco animais de cada sexo.

Todos os animais apresentaram-se normais ao exame clínico e à avaliação da pressão sanguínea por meio do método oscilométrico, em aparelho Dixtal DX2010. Após as avaliações clínica e pressórica, foram administrados $2 \mathrm{mg} \mathrm{kg}^{-1}$ de cloridrato de ranitidina em veículo composto por fenol, fosfato de sódio dibásico, fosfato de potássio monobásico e água para injeção (Ranitidina 50mg $2 \mathrm{ml}^{-1}$ - União Química ${ }^{\circledR}$ ), na veia cefálica, em bolus (aproximadamente um segundo de infusão).
As pressões sanguíneas sístólica, diastólica e média foram também mensuradas 10 minutos e quatro horas após a administração do fármaco, no membro pélvico esquerdo. Os animais eram observados por oito horas, sendo anotados os sinais clínicos e as atitudes de cada animal em ficha individual.

Na análise estatística, por se tratar de dados não paramétricos, foi feita uma codificação dos sinais clínicos observados em quatro classes: (1) animal normal; (2) animal apresentando apatia; (3) animal apresentando salivação; (4) animal apresentando apatia, salivação, mímica de vômito ou êmese.

Na comparação dos efeitos colaterais entre sexos, aplicou-se o teste de Mann \& Whitney. Na avaliação entre os cães das raças Beagle, Retriever do Labrador e os animais sem raça definida (SRD), utilizouse o teste de Kruskal \& Wallis. Os valores pressóricos foram avaliados por comparação de pares, a 5\% do teste de T de Student, considerando como padrão para as comparações as pressões obtidas antes da aplicação do fármaco.

\section{RESULTADOS E DISCUSSÃO}

De acordo com a graduação utilizada, 13,3\% dos animais pertenciam à classe $1 ; 6,7 \%$ enquadravamse na classe 2; $50 \%$ dos animais eram da classe 3 , e a classe 4 continha $30 \%$ dos animais. Esses sinais foram observados até 40 minutos após a aplicação da ranitidina e estão ilustrados na figura 1. Não há nenhum relato na literatura veterinária sobre possíveis efeitos colaterais da aplicação de ranitidina em cães. Em seres humanos, esse fármaco, utilizado em dose terapêutica, não causa efeitos colaterais, como o vômito (HONG, 2006).

Os animais apresentaram-se normotensos ao exame pressórico, não havendo diferenças nas medidas de pressão sanguínea verificadas 10 minutos e quatro horas após a aplicação da ranitidina, nos animais estudados. Caso houvesse diminuição da pressão arterial, após a aplicação do fármaco, existiria outro indicativo de que a ranitidina a $2 \mathrm{mg} \mathrm{kg}^{-1}$, intravenosa, em bolus, é sobredose em cães (Tabela 1). Os efeitos cardíacos dos antagonistas $\mathrm{H}_{2}$ só são detectados em indivíduos em estado de choque (CHRUSCH et al., 1999), não havendo evidências de estímulo arritmogênico (UPRICHARD \& HARRON, 1990) nem de alteração na pressão sanguínea em 


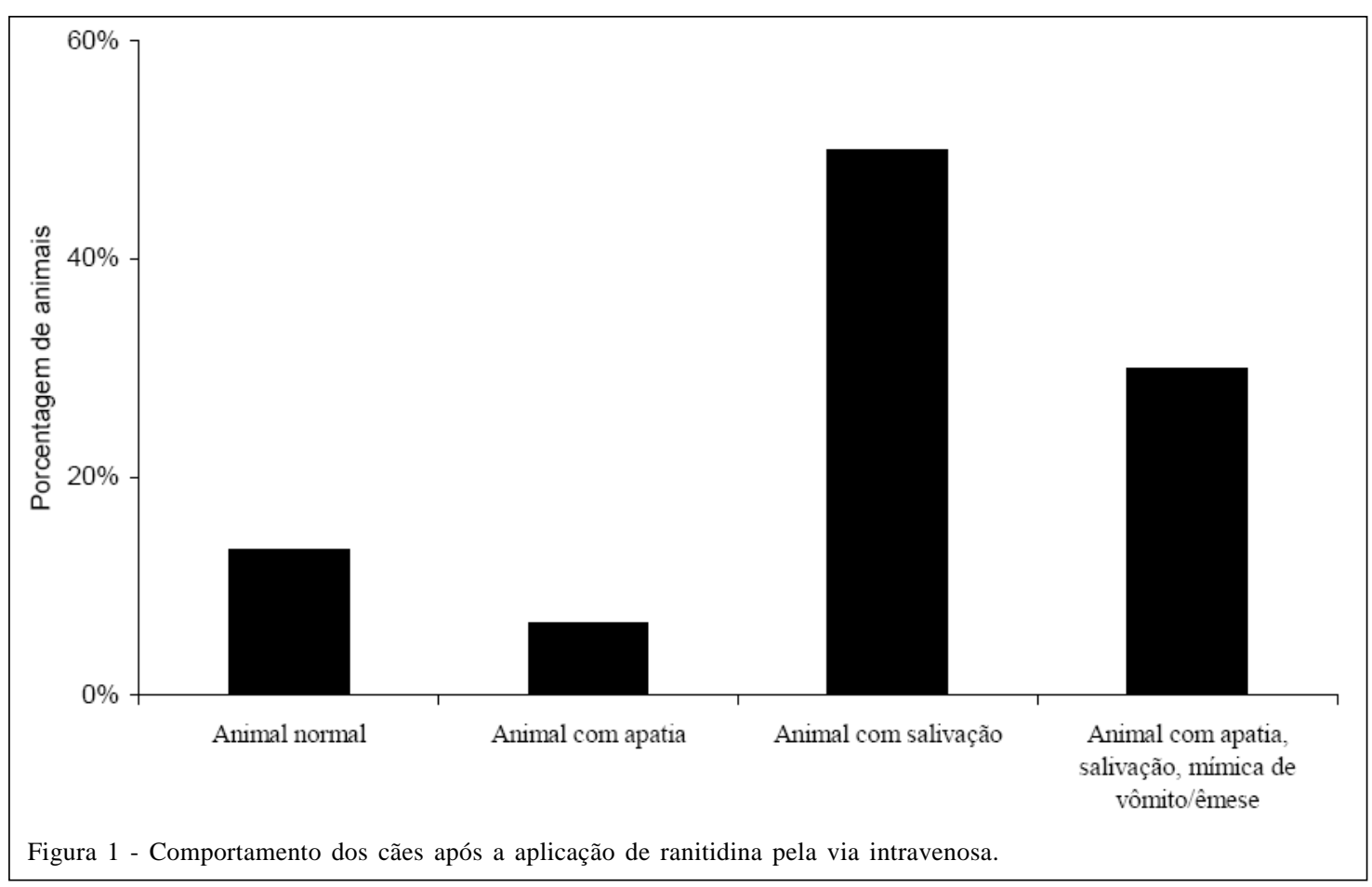

pacientes saudáveis (MCCORD et al., 2006). Porém, há relatos de desenvolvimento de alterações em sistema nervoso central de seres humanos, como letargia, desorientação, sonolência e confusão, principalmente nos idosos ou em indivíduos com função renal diminuída (SLUGG et al., 1992; EINSIEDEL et al., 2002).

Não houve diferença estatística entre sexos ( $\mathrm{T}=221$, sendo $\mathrm{T}$ crítico=186) nem entre os cães sem raça definida, os cães da raça Beagle e os cães da raça Retriever do Labrador ( $\mathrm{T}=1,032$, que é menor que o $\mathrm{T}$ tabelado de 5,99). Isso mostra que não há diferença entre os diferentes biotipos na apresentação dos sinais clínicos, nas condições em que foi realizado o experimento (Figura 2).

Porém, os animais menores (os cães da raça Beagle e os cães sem raça definida) apresentaram valores numéricos codificados iguais e levemente maiores que os cães da raça Retriever do Labrador
(168 e 129, respectivamente), o que não era de se esperar, já que animais maiores necessitam de doses proporcionalmente menores para exibirem efeitos colaterais (VIANA et al., 2006).

\section{CONCLUSÕES}

Concluiu-se que o uso de ranitidina, na dose terapêutica de $2 \mathrm{mg} \mathrm{kg}^{-1}$, aplicada via intravenosa, pode provocar apatia, salivação, mímica de vômito e êmese, não havendo diferença nos sinais clínicos observados entre sexo nem entre os diferentes biotipos caninos estudados.

\section{COMITÊ DE ÉTICA E BIOSSEGURANÇA}

Este experimento foi aprovado em assembleia departamental e registrado na Pró-reitoria de Pesquisa da Universidade Federal de Lavras sob registro n.1639/2006.

Tabela 1 - Médias e desvio padrão das pressões arteriais sistólica, média e diastólica antes e após a aplicação da ranitidina, em cães das raças Retriever do Labrador, Beagle e em cães sem raça definida.

\begin{tabular}{|c|c|c|c|}
\hline & $\begin{array}{l}\text { Pressão arterial sistólica } \\
\text { (média } \pm \text { desvio padrão) }\end{array}$ & $\begin{array}{l}\text { Pressão arterial diastólica } \\
\text { (média } \pm \text { desvio padrão) }\end{array}$ & 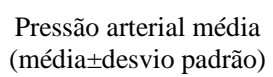 \\
\hline Antes & $126,64 \pm 12,15^{\text {a }}$ & $88,64 \pm 13,15^{b}$ & $103,54 \pm 12,13^{c}$ \\
\hline 10 minutos após & $122,34 \pm 15,31^{a}$ & $87,94 \pm 15,20^{b}$ & $98,26 \pm 14,98^{c}$ \\
\hline 4 horas após & $124,39 \pm 8,82^{\mathrm{a}}$ & $87,17 \pm 8,73^{b}$ & $103,66 \pm 11,32^{\mathrm{c}}$ \\
\hline
\end{tabular}

Letras iguais, na mesma coluna, representam igualdade estatística a 5\%. As pressões foram medidas em mmHg.

Ciência Rural, v.40, n.2, fev, 2010. 


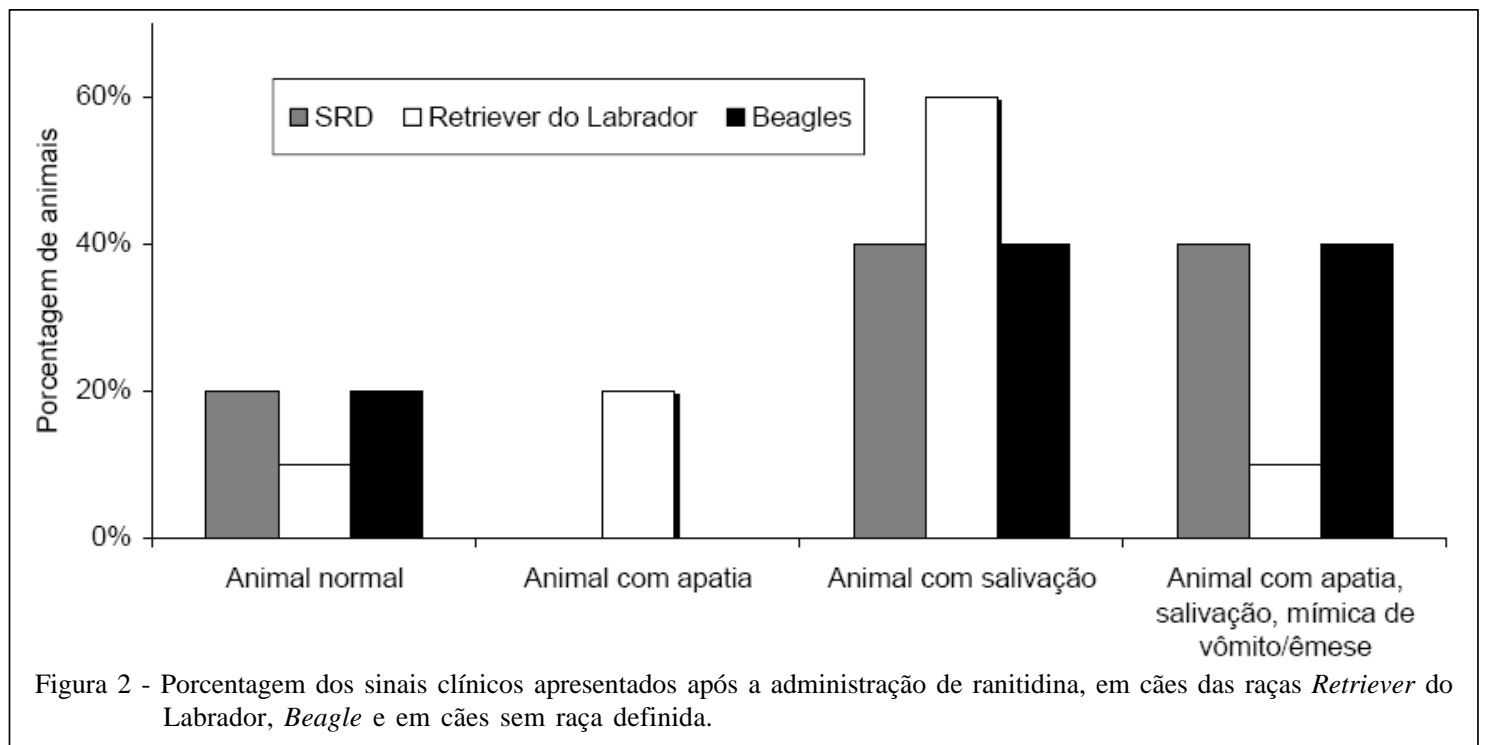

\section{REFERÊNCIAS}

CANANI, R.B. et al. Therapy with gastric acidity inhibitors increases the risk of acute gastroenteritis and communityacquired pneumonia in children. Pediatrics, v.117, p.817820, 2006.

CHRUSCH, C. et al. Histamine H3 receptor blockade improves cardiac function in canine anaphylaxis. American Journal of Respiratory and Critical Care Medicine, v.160, p.11421149, 1999

EINSIEDEL, R.W.V. et al. H -Histamine antagonist (Famotidine) induced adverse CNS reactions with long-standing secondary mania and epileptic seizures. Pharmacopsychiatry, v.35, n.4, p.152-154, 2002.

ELZINGA-HUTTENGA, J. et al. Movement disorders induced by gastrointestinal drugs: two pediatric cases. Neuropediatrics, v.37, p.102-106, 2006.

ETTINGER, S.J.; FELDMAN, E.C. Tratado de medicina interna veterinária: doenças do cão e do gato. 4.ed. São Paulo: Manole, 1997. 3020p.

HONG, J.Y. Effects of metoclopramide and ranitidine on preoperative gastric contents in day-case surgery. Yonsei Medical Journal, v.47, p.315-318, 2006.
ISHIKAWA, H. et al. FR145715, a novel histamine $\mathrm{H}$ receptor antagonist, with specific anti-Helicobacter pylori activities. European Journal of Pharmacology, v.378, p.299-310, 1999.

McCORD, J.L. et al. $\mathrm{H}_{2}$-receptor-mediated vasodilatation contributes to postexercise hypotension. Journal of Applied Physiology, v.100, p.67-75, 2006.

OKABE, S. et al. Pharmacological regulation of gastric acid secretion in the apical membrane of parietal cells; a new target for antisecretory drugs. Journal of Physiology and Pharmacology, v.52, p.639-656, 2001.

SLUGG, P.H. et al. Ranitidine pharmacokinetics and adverse central nervous system reactions. Archives of Internal Medicine, v.152, p.2325-2329, 1992.

SPINOSA, H.S. Medicamentos que interferem com as funções gastrintestinais. In: SPINOSA, H.S. et al. Farmacologia aplicada à medicina veterinária. Rio de Janeiro: GuanabaraKoogan, 1996. p.321-332.

UPRICHARD, A.C.G.; HARRON, D.W.G. H -receptor antagonism is not pro-arrhythmic in a chronic canine model. Basic Research in Cardiology, v.85, p.519-530, 1990.

VIANA, F.A.B. et al. Prescrição médico-veterinária. In: Fundamentos de terapêutica veterinária. Belo Horizonte: FEPMVZ, 2006. p.5-31. 